\title{
EL PODER ANTE LA CRISIS DE GOBERNABILIDAD EN MÉXICO
}

\author{
Asael Mercado Maldonado ${ }^{1}$ \\ Germán García Rivas Garduño \\ Universidad Autónoma del Estado de México
}

Resumen: El presente artículo tiene como objetivo explicar la operatividad del poder como elemento fundamental de la estructura del estado al que pertenece, destacando el enfoque de Edgar Bodenheimer aplicando su visión a la interpretación de los fenómenos políticos y sociales que se presentan en México. Como la crisis de la gobernabilidad, la corrupción y violencia, del poder cada día creciente del narcotráfico, de los actos de impunidad y del crecimiento de la pobreza extrema. El teórico sostiene que; La historia del Derecho es la historia de la lucha por el poder. El Derecho es el intermediario entre la Anarquía y el Despotismo. La relación entre los desiguales es de subordinación y entre los iguales es de Derecho.

Palabras clave: Derecho, poder, estado, despotismo, anarquía, crisis, totalitarismo

Abstract: This article aims to explain the operation of power as a fundamental element of the state structure to which it belongs, highlighting the focus of Edgar Bodenheimer applying his vision to the interpretation of political and social phenomena that occur in Mexico. As crisis of governance, corruption, violence, every day growing power of drug trafficking, acts of impunity and the growth of extreme poverty. The theory argues that legal history is the history of the struggle for power. The law is the intermediary between anarchy and despotism. The relationship between unequals is subordination and among peers is of law.

Keywords: Law, power, status, despotism, anarchy, crisis, totalitarianism

\section{INTRODUCCIÓN}

Muchas veces nos hemos preguntado, ¿por qué generalmente asociamos la cuestión del poder con la maldad? ¿Qué es el Poder? ¿Qué factores históricos hicieron posible su existencia en nuestras sociedades? ¿Qué relación existe entre la compleja naturaleza humana y la organización social?

1 Doctor en Ciencias Sociales y Políticas de la Universidad Iberoamericana, actualmente se desempeña como Profesor de Tiempo Completo "F" adscrito a la Fac. de Ciencias Políticas y Sociales de la Universidad Autónoma del Estado de México

2 Maestro en Derecho de la Universidad Autónoma del Estado de México, actualmente se desempeña como Profesor de Tiempo Completo "C" de la Dirección de Estudios de Nivel Medio Superior UAEM y como Profesor de Asignatura de la Facultad de Derecho Universidad Autónoma del Estado de México UAEM 
Si las estructuras de poder son el cáncer de las sociedades contemporáneas, ¿Por qué mantienen al hombre en cautiverio de sí mismo? ¿Cuál sería el camino de emancipación social?

Edgar Allan Poe, escritor bostoniano que con profunda intensidad y delirante redacción, escudriñó interesantes aspectos de la naturaleza humana como la maldad, el miedo y la perversión; alguna vez dijo: "Yo creo que la perversidad es uno de los primitivos impulsos, del corazón humano; Una de las facultades o sentimientos elementales que dirigen el carácter del hombre." ¿Quién no se ha sorprendido cien veces cometiendo una acción sucia o vil, por la sola razón de saber que no la debía cometer?" "No tenemos una perpetua inclinación; no obstante la excelencia de nuestro juicio, a violar lo que a la ley, sencillamente porque comprendemos lo que es ley" (Poe, 1988: 192).

Bien y mal existen en la voluntad y naturaleza humana, de sus defectos y virtudes surge el diseño y modelo mediante el cual los hombres construyen la organización social. De ahí la importancia de conocer las entrañas del poder, de indagar sobre su estructura interna. Descubrir sus mecanismos; sicológicos, políticos y culturales así como sus extrañas formas de vestir.

En las sociedades contemporáneas, los hombres son actores de una comedia que tiene un nombre: EL PODER. Entre sus víctimas se encuentran Calígula, Nerón, Atila, Iván IV, Hitler y Stalin, todos ellos además de mostrarse humildes ante él, son sólo sus miserables sirvientes.

Nuestras sociedades están al servicio del poder porque permiten su consolidación, legitimación y reproducción. Paulatinamente, cada vez más se degradan y corrompen, el delito le es consustancial. La historia muestra cómo han prevalecido sobre la humanidad y sus gobiernos -catastróficamente- formas de vida y mecanismos políticos que obstaculizan los procesos de libración.

Entre los mecanismos que atrofian la humanización de la sociedad están la burocratización de las instituciones, la impunidad de los gobernantes, la competencia Individualista, la racionalidad lucrativa y consumista, la corrupción administrativa y la política inmoral. Todos esos mecanismos contienen un designio trágico porque explican la dominación y nos muestran la realidad que la humanidad vive.

Los tiranos mueren, él permanece, las sociedades crecen, él se transforma, las épocas con su música y cultura pasan pero él se consolida diversificándose. Está presente en los lujosos aposentos de la Casa Blanca o en el camión del proletario, en las oficinas, del Kremlin y en la sala cinematográfica o en el aula de clases. Todos, hablan aunque con distintas palabras del mismo fenómeno: El Poder.

Uno de los compromisos que tiene todo individuo como ciudadano de un estado y más cuando ejerce la profesión de cientista social es el de interpretar, comprender y explicar los fenómenos que se dan dentro de la estructura del estado al que 
pertenece, encontramos en la obra de Edgar Bodenheimer (2005) una fuente teórica para realizar el trabajo de comprensión e interpretación de los fenómenos políticos y sociales que se presentan en el Estado Mexicano actual como la crisis de gobernabilidad. Más adelante se considerarán principios representativos de su pensamiento y se aplicarán con la situación actual del estado mexicano, sorprendentemente se ajustan a lo que ocurre cotidianamente lo que permite realizar una labor de interpretación y hasta de proyección en el devenir político y social del pueblo mexicano.

\section{I.- QUÉ ES EL PODER}

Objeto privilegiado de la Ciencia Política cuando hablamos de poder debemos considerar la cuestión del Estado. Porque el poder del Estado es la capacidad de asignar autoritativamente los valores a una sociedad en conjunto. El Estado es el poder político de una nación estructurado jurídicamente e institucionalizado. Según Hobbes en el Leviatán, encontramos que el poder de un hombre consiste en poseer medios para obtener algún bien manifiesto futuro.

El poder puede ser NATURAL o INSTRUMENTAL. El poder Natural es la eminencia de las facultades del cuerpo o de la inteligencia, tales como la Fuerza, Belleza, Prudencia, Aptitud, Elocuencia, Liberalidad o Nobleza extraordinaria. El poder instrumental se adquiere por los antedichos o por la Fortuna sirviendo como medios e instrumentos para adquirir más, como la Riqueza, la Reputación, los Amigos, y los secretos designios de Dios, lo que los hombres llaman Buena Suerte. Pero... "el mayor de los poderes humanos es el que se integra con los poderes de varios hombres unidos por el consentimiento en una persona natural 0 civil; tal es el poder de un ESTADO" (Hobbes, 1997: 69).

Hobbes defiende la causa del poder absoluto no en nombre del derecho divino de los reyes, sino en nombre del interés de los individuos, en aras de la conservación y la paz. Para asegurar la paz y seguridad de los hombres, se debe establecer entre ellos un contrato y transferir al Estado sus derechos individuales. Pero dada la naturaleza humana el acuerdo (contrato) no será observado por todos a menos que un poder visible armado de castigo actúe sobre los hombres atemorizándolos. Es así como los hombres llegan a formar y respetar a la sociedad por temor al castigo.

Aparentemente, en el Estado más autoritario el hombre alcanza su mejor desarrollo realizándose la felicidad, el placer y bienestar. Esta propuesta nos permite vincular el Poder con el Bien. Es decir cuando el Poder todavía no se corrompe -en su ejercicio- para el beneficio de unos cuantos. Por eso considero válida la fundamentación de la siguiente definición; Poder es fuerza y autoridad, capacidad física de mando y capacidad ético-jurídica de autoridad para lograr la cohesión social. 
En el hombre y en la sociedad existen dos intereses contrapuestos. De un lado está el YO individualista, captativo, anti-social al que no le importan los demás y por otro está el NOSOTROS solidario, comunitario que trata de establecer un consentimiento con los demás para convivir armónicamente y en forma organizada. En este escenario conflictivo es imperativa la necesidad del poder, como un agente que consigue instaurar la Cohesión Social (Neira, 1999: 26).

El poder se convierte en una necesidad social por el orden que impone y el concierto que instaura. El poder en este sentido permite a los hombres alcanzar una vida mejor. El poder mantiene juntos los elementos sociales de dos formas; Por medio de la coacción o por medio de la persuasión. El poder obtiene como sea, la obediencia de la comunidad con miras al bien de todos. De lo contrario el grupo humano corre el riesgo de dividirse y anarquizarse. Los grupos sociales se someten o bien por la fuerza externa de la violencia o bien por la energía interna de las convicciones.

El poder tiene las dos caras de Jano (Moneda Romana). Por un lado es POTESTAS-Fuerza, capacidad efectiva de hacerse obedecer por todos aún por los apáticos, y por otro lado es AUTORITAS-Capacidad de mando con título legítimo, capacidad que tiene el derecho de exigir razonablemente la obediencia de todos para bien común. Duverger sintetiza; Todo poder es una mezcla de violencia y de creencias.

Para Bodenheimer el poder se presenta cuando existe una relación de dominación y de sujeción entre un individuo y otro o entre un grupo y otros grupos, en donde el que domina no tiene ninguna obligación para con el subordinado, quedando éste sometido a la voluntad arbitraria e ilimitada de su dominante (Bodenheimer, 2005).

El poder puede considerarse como la autoridad que posee un individuo o un grupo determinado para mandar y hacerse obedecer, si éste grupo llegase a obtener la confianza de seguidores para lograr sus fines, podría tener una consolidación y apoderarse de un territorio, una región e incluso de un Estado y moldearlo y someterlo de acuerdo a sus intereses, debido a que el poder tiende a extenderse 0 avanzar hasta donde pueda llegar, y entonces nos encontraríamos con el fenómeno llamado Estado totalitario (Bodenheimer 2005).

Difícilmente podría negarse que la voluntad por alcanzar el poder sea una de las fuerzas motivadoras más intensas que mueven a los individuos. En nuestro país tenemos tres casos de cómo la ambición por el poder motiva para realizar toda clase de acciones; La famosa "caída del sistema en la elección en donde contendieron Carlos Salinas de Gortari y Cuauhtémoc Cárdenas", el "reconocimiento del triunfo de Fox por parte de Zedillo aún antes de que concluyera el conteo de votos, hecho que incluso priistas destacados recriminaron a Zedillo y finalmente la escandalosa serie de actos ilegales que se presentaron en la última elección del 2006 independientemente de los contendientes y de sus características. 
Existen dos formas extremas de influencia ilimitada de poder, una la anarquía y la otra el despotismo, ambas son formas de poder incontrolado.

\section{II.- CONFORMACIÓN DEL PODER POLÍTICO, EL ESTADO Y LAS ELITES}

"El arte del hombre fabricó un animal artificial, ese gran Leviatán que se llama cosa pública o Estado. Es un hombre artificial creado para la protección y defensa del hombre natural. La opulencia y las riquezas de los particulares son su fuerza. La equidad y las leyes son para él una razón y voluntad artificial. Y la guerra civil sería su muerte" (Chevallier, 1977: 51).

La Teoría Liberal contrapuesta al absolutismo explicó claramente la nueva lógica de la Dominación Capitalista; El poder político en las democracias pluralistas tiene un carácter de clase. La teoría liberal contractualista establece por una parte que el salario liga al trabajador eternamente a su condición de asalariado, y por otra el capital como contrapartida del salario hace lo mismo con el patrón. A partir de estas premisas se construye un círculo político donde el poder de la clase burguesa se manifiesta en la conformación de un Estado ceñido estrechamente a la propiedad. Excluidos los asalariados del poder político, el poder aparece como la capacidad de los propietarios para consolidar sus intereses. El sistema es perfecto, y no hay nada en el parecido a la lucha de clases. A lo más las diferencias se dan entre los propietarios mismos. $Y$ toda la legislación protegerá al sistema de propiedad (Torres, 1998: 28-29).

Después de las Grandes revoluciones políticas -Inglesa, Francesa y Norteamericana siglos XVII y S. XVIII- que dieron origen al Estado temporáneo desapareció gradualmente la autoridad Externa-Manifiesta y se consolidó la autoridad Interna-Anónima. El control social de los dominantes no sólo radicó en las instituciones, penetró hasta la misma conciencia individual.

Con las victorias políticas de la clase media en ascenso la autoridad exterior perdió su prestigio y la conciencia del hombre ocupó el lugar que aquella tenía antes. Someterse a órdenes nacidas de un poder exterior (institucional) pareció ser algo indigno de un hombre libre; pero la sumisión a sus propias inclinaciones morales y el aparente dominio sobre sí mismo pareció construir la esencia misma de la libertad. Sin embargo, el análisis demuestra que el gobierno de la conciencia puede llegar a ser aún más duro que el de las autoridades exteriores. La autoridad que necesita el poder para aplicarse más que haber desaparecido se hizo invisible. "Se disfraza de sentido común, ciencia, responsabilidad, moral, salud psíquica, normalidad, opinión pública" (Torres, 1998: 114-115).

Se considera a la élite como un grupo que asciende a posiciones de 'liderato' e influencia en todos los niveles sociales; se encumbran, como líderes de clase en la estructura social. Concebimos al 'líder' en un sentido amplio, para nombrar a jefes, oficiales y otras personalidades que por alguna razón, ejercen autoridad sustantiva sobre las actitudes y la conducta social en general. 
Vilfredo Pareto otorgó a la noción de élite carta de ciudadanía en la Sociología. La élite está compuesta por todos aquellos que manifiestan cualidades excepcionales o dan pruebas de aptitudes eminentes en su dominio propio o en una actividad cualquiera. Pareto define a la élite como integrada por miembros 'superiores' de una sociedad a quienes sus cualidades eminentes auguran poder o prestigio. En la clase social hay divisiones que a su vez poseen un grupo selecto, es aquí donde la élite se forma por prioridad dentro de la lucha de clases, donde el poder combina astucia y fuerza emanada de directores, empresarios y sus asociados políticos, los llamados dirigentes de una nueva sociedad. La esencia de la élite es la superioridad, donde el régimen político está ligado con la clase gobernante y su propia circulación ${ }^{3}$ para mantenerse en el poder que dependerá del predominio de los residuos de estratos inferiores.

Para R. Miliband, el gobierno, la administración, el instituto armado, la policía, el poder judicial, el gobierno subcentral y las asambleas parlamentarias son las instituciones que conforman el Estado; y son las personas como los presidentes, altos jefes, miembros del gabinete, altos servidores públicos, jueces, y de más gente de rama, quienes constituyen la élite del Estado. "Aunque hay muchos hombres con poder fuera del sistema estatal, que afecta al Estado, no son ellos los depositarios reales del poder estatal, y para analizar el papel desempeñado por el Estado en estas sociedades, es necesario estudiar a la élite estatal, que esgrime el poder del Estado como entidad distinta aparte" (Miliband, 1983: 55) El Estado aparece como un conjunto de instituciones que posee solo una parte subsidiaria de la mayor actividad económica dominada por la propiedad y empresas privadas, donde existe una pluralidad de élites económicas en la sociedad capitalista y su conformación como clase dominante cuida sus propios intereses comunes, ya que los hombres de negocios en el estado son una minoría poderosa. Hoy que tanto se habla de democracia, la mayoría es administrada, representada y juzgada por personas procedentes de otras clases económicas superiores.

Wright Mills menciona tres élites importantes: Económica, Política y Militar. "En la cumbre de la economía, entre los ricos corporativos, es decir, entre los grandes accionistas de las grandes compañías corporativas, están los altos jefes ejecutivos; en la cumbre del orden político, los individuos del directorio político; y en la cumbre de la institución militar, la élite estadista como soldados agrupados en el Estado Mayor Unificado en el escalón más alto del ejército. Cada uno de esos dominios se vincula con los otros, las decisiones tienden a ejercerse, los principales individuos de cada uno de los tres dominios de poder -los señores de la guerra, los altos jefes de las empresas, el directorio político-, tienden a unirse, a

\footnotetext{
3 La circulación es aquel proceso continuo de mezcla donde los antiguos asimilan a los nuevos integrantes de la élite, sin haber una reposición sino una integración. Existen dos movimientos en la circulación; 1) Los individuos de los estratos inferiores que consiguen acceder a una élite establecida 2) Individuos de estratos inferiores que forman nuevas élites; y así, se produce el movimiento de la circulación de las élites para restablecer el equilibrio generacional.
} 
formar la minoría del poder" (Wright, 1993: 16). Impera una minoría de personas que retienen el poder para sí mismas, una clase dominante que puede utilizar la fuerza para mantener una estructura y organización.

El máximo poder reside en los dominios económico, político y militar. El orden económico anteriormente disperso en unidades de producción ha llegado a estar dominado por 300 compañías relacionadas administrativa y políticamente, poseen las claves de resoluciones económicas: el orden político antes diseminado en estados, es una institución ejecutiva centralizada que ha controlado varios poderes en grupos, organizaciones e instituciones, para penetrar toda la estructura social: por último el orden militar, se ha convertido en una severa instancia de vigilancia del orden y verifica el cumplimiento de los mandatos del dominio burocrático. En cada orden se ha formado una élite que es vista como un círculo de personas con carácter y energía. Monopolizan el poder, la riqueza y el prestigio.

Es una élite política formada por la coincidencia de intereses entre los que dominan los medios de producción y los que controlan los instrumentos de violencia, y el ascenso al mando político de dirigentes corporativos y militares.

El poder de la élite militar en México está vinculado al poder político quien en última instancia orienta las acciones de la organización militar. El control de la élite militar se logra mediante una red impermeable y vigorosa; la integran 17 generales unidos por tres preceptos sagrados: mandar, obedecer y callar. La influencia de mando circula por múltiples canales que tienen una matriz de origen: el despacho del general secretario. Desde ahí, se distribuye en cascada hacia 12 regiones militares, 44 zonas, 23 guarniciones y 19 bases aéreas. El ejército tiene 175 mil hombres y mujeres que trabajan pacientemente por un objetivo: mantener el orden social $^{4}$. Es importante señalar que en la reciente guerra del narcotráfico han sido asesinados importantes generales, coroneles y tenientes retirados del ejército mexicano que ocupaban cargos de dirección en policías locales en la cd. del Paso en Nuevo León. Ha llegado a tal grado el clima de violencia que en cd. Juárez, Tamaulipas, La ciudad ha visto 2,926 asesinatos hasta ahora este año (2011), y cerca de 7,303 desde enero de 2008. En octubre, trece personas fueron asesinadas en un solo día, y a la mañana siguiente un autobús que llevaba trabajadoras a una de las cientos de maquiladoras que rodean la ciudad fue atacado por sicarios. Un informe de El Colegio de la Frontera Norte publicado en enero reveló que existen 116,000 casas deshabitadas en toda la ciudad, de un total de 416,000 unidades. Según el informe, "la despoblación incrementó en gran medida en los dos años anteriores debido a la violencia y la inseguridad. Muchos migrantes que vinieron del sur de México a trabajar en la industria maquiladora han decidido regresar a sus lugares de origen. Otros han migrado a Estados Unidos". Más de 10,670 negocios han cerrado desde 2008, dejando muchos edificios de fábricas vacíos pero, dadas las actuales condiciones, invendibles a

\footnotetext{
${ }^{4}$ Tomado del sitio Web www.todito.com/paginas/noticias/37849 consultado el día 13 de Marzo de 2002.
} 
ningún precio.(Vulliamy, 2011: 4-5). Existen para el 2011, 26,000 casas abandonadas por familias que han salido huyendo a otras partes de la república. En esa ciudad del crimen se han presentado matanzas impresionantes.

El poder de la milicia radica en el rigor de su organización, son una fuerza independiente, entre sus filas podemos encontrar grupos de inteligencia cuya arma es la información de gran valor para líderes políticos; destaca entre sus filas la fuerza armada de vital importancia para disciplinar a grupos inconformes con el sistema y mantener la seguridad. La élite militar es el pilar del poder político y éste a su vez depende de la milicia para mantener la estabilidad nacional.

La élite política ejerce el poder político en la figura del Estado, su campo de acción es la administración pública "y ejercerá influencia en los círculos donde se hace política, es decir en los grupos políticos; pero no solamente bastará ingresar a un grupo político, sino que además es muy importante que este grupo se distinga por su fortaleza" (Salim \& Ramírez, 1987: 32). La clase política mexicana es "el grupo socialmente dirigente y políticamente hegemónico del Estado, que no coincide necesariamente con la clase económica dominante, ni con su fracción predominante". "Es una minoría netamente política que deriva su poder de la monopolización de la gestión gubernamental y del manejo de los recursos públicos, lo que la lleva, incluso, a establecer reglas de ascenso y mecanismos de control sobre los distintos grupos y subgrupos políticos" (Salim \& Ramírez, 1987: 115).

Desde el sexenio de Miguel de la Madrid y Carlos Salinas de Gortari el gobierno enviaba al CMHN un informe preciso del manejo de las finanzas públicas, reprivatizaciones y manejo de indicadores macroeconómicos. Consolidados como grupo los empresarios mantuvieron su política económica, con presencia institucional y ejercieron presión para diseñar el contenido de las políticas públicas.

Cuadro de la élite del poder empresarial en México:

\begin{tabular}{|c|l|l|}
\hline No. & NOMBRE & EMPRESA \\
\hline 1 & CARLOS SLIM HELÚ & Grupo Carso, Telmex \\
\hline 2 & EUGENIO GARZA LAGÉRA & FEMSA KOF \\
\hline 3 & LORENZO H. ZAMBRANO TREVIÑO & Cemex \\
\hline 4 & ANTONINO FERNÁNDEZ RODRÍGUEZ & Grupo Modelo \\
\hline 5 & EMILIO F. AZCÁRRAGA JEAN & Grupo Televisa \\
\hline 6 & CLAUDIO X. GONZÁLEZ LAPORTE & Kimberly Clark \\
\hline 7 & ROBERTO GONZÁLEZ BARRERA DE HANK & $\begin{array}{l}\text { Grupo Maseca, Grupo Financiero } \\
\text { Banorte }\end{array}$ \\
\hline 8 & $\begin{array}{l}\text { DANIEL SERVITJE MONTULL Y ROBERTO SERVITJE } \\
\text { SENDRA }\end{array}$ & Grupo Bimbo \\
\hline 9 & RICARDO B. SALINAS PLIEGO & $\begin{array}{l}\text { Televisión Azteca, Electra, } \\
\text { Movilacces, Dataflux }\end{array}$ \\
\hline 10 & ALBERTO BAILLÉRES GONZÁLEZ & Grupo Bal \\
\hline 11 & MARÍA ASUNCIÓN ARAMBURUZABALA & Tresalia Capital, Modelo \\
\hline 12 & FRANCISCO JAVIER Y RICARDO MARTÍN BRINGAS & Soriana \\
\hline
\end{tabular}




\begin{tabular}{|c|l|l|}
\hline 13 & MAX MICHEL SUBERVILLE & Liverpool \\
\hline 14 & OLEGARIO VÁZQUEZ RAÑA & Grupo ángeles \\
\hline 15 & ISAAC SABA RAFFOUL & Grupo Saba, Unefon \\
\hline 16 & LUIS BERRONDO ÁVALOS & $\begin{array}{l}\text { Mabe, Grupo Financiero Vital, } \\
\text { Mexchem }\end{array}$ \\
\hline 17 & CYNTHIA H. GROSSMAN & Grupo Continental \\
\hline 18 & DIONISIO GARZA MEDINA & Alfa \\
\hline 19 & GUILLERMO GONZÁLEZ NOVA & Comercial Mexicana \\
\hline 20 & CARLOS PERALTA QUINTERO & IUSA \\
\hline 21 & ÁNGEL LOSADA GÓMEZ & Gigante \\
\hline 22 & GERMÁN LARREA MOTA VELASCO & GrupoMéxico,Comercial Mexicana \\
\hline 23 & FERNANDO SENDEROS MESTRE & Desc. \\
\hline 24 & EUGENIO CLARIOND GARZA & Grupo IMSA \\
\hline 25 & MIGUEL RINCÓN ARREDONDO & Corporación Durango \\
\hline 26 & ALEJANDRO SOBERÓN KURI & CIE \\
\hline 27 & MIGUEL ANTONIO FERNÁNDEZ ITURRIZA & Embotelladora Argos \\
\hline 28 & ENRIQUE C. MOLINA SOBRINO & Pepsi, Gemex \\
\hline 29 & GERMÁN Y LUIS AHUMADA RUSSEK & Consorcio Ara \\
\hline 30 & ALEJANDRO BURILLO AZCÁRRAGA & Grupo Financiero IXE, Pegaso \\
\hline 31 & JOSÉ SERRANO SEGOVIA & Grupo TMM \\
\hline 32 & ISIDRO LÓPEZ DEL BOSQUE & Grupo Industrial Saltillo \\
\hline 33 & ENRIQUE ROBINSON BOURS ALMADA & Bachoco \\
\hline 34 & JUAN BOSCO MALDONADO QUIROGA & Copamex \\
\hline 35 & EDUARDO TRICIO HARO & Grupo Industrial Lala \\
\hline 36 & ANTONIO Y ALFREDO CHEDRAUI OBESO & Grupo Comercial Chedraui \\
\hline 37 & PABLO ESCANDÓN CUSI & Controladora de Farmacias Grupo \\
& & Acción, Nadro. \\
\hline 38 & GASTÓN AZCÁRRAGA ANDRADE & Grupo Posadas \\
\hline 39 & ENRIQUE COPPEL LUKEN & Almacenes Coppel Canadá \\
\hline 40 & RUFINO VIGIL GONZÁLEZ & ICH, Simec \\
\hline & & \\
\hline
\end{tabular}

Fuente: sitio Web www.foros.fox.presidencia.gob.mx consultado el 17 de Septiembre de 2002

Antes los empresarios presentaban puntos de vista al presidente y su gabinete, ahora se cambian los papeles son los funcionarios y secretarios los que presentaban al Consejo informes de avances en materia de política económica y sus estrategias para lograr sus metas.

La actuación del CMHN en el gobierno de Ernesto Zedillo fue prolífica, anunciaron la presentación de proyectos de inversión, exportación y creación de empleos aunado a que los grupos empresariales que integran el organismo invertirían millones de dólares, incorporando la inversión extranjera y la industria mediana y pequeña; dando paso firme a la recuperación y promoviendo la inversión de los propios empresarios mexicanos al país. Zedillo declaró que democracia y crecimiento, son procesos complementarios, "son benéficos para el pueblo de México, pues la democracia significa la oportunidad de elegir con tal libertad a quienes habrán de representar a los ciudadanos en los órganos de gobierno, y el crecimiento es la base material del bienestar social" (La Jornada, 1997). 
Vicente Fox fue un presidente atado a los intereses de los grandes líderes empresariales del país, fácilmente olvido su retórica que desarrolló en su campaña presidencial. Al presidente le impusieron desde las esferas empresariales la política económica y la política política.

El balance del sexenio foxista es lamentable; de acuerdo con Julio Boltvinik, la población pobre de México brinco al $69.8 \%$ de la población total en 1984; al 75.8\% en 1994 y al 76.9\% en el 2000 (Calva, 2005: 6) El desempeño de la economía nacional durante el cuatrienio 2001-2004 ha resultado notoriamente mediocre. La oferta de un crecimiento económico sostenido a una tasa del $7 \%$ anual y de generar 1.3 millones de empleos por año, contrasta con un crecimiento de apenas $1.5 \%$ anual, así como en la pérdida de 223,005 empleos formales (registrados en el IMSS) durante el primer cuatrienio del gobierno del cambio (Calva, 2005: 41).

Las condiciones del CMHN prevalecieron para regular la vida de México en política monetaria, financiera y fiscal. Además provocaron el proceso del "desafuero" y la campaña negra contra el excandidato presidencial de la izquierda Andrés Manuel López Obrador. El año 2006 eminentemente político electoral fue también testigo de bochornosos actos que involucraron a la familia presidencial, a los tres principales candidatos presidenciales -Obrador, Madrazo y Calderón-, y a varios gobernadores como Arturo Montiel y Ricardo Monreal. El año concluyó con resultados electorales turbios y cuestionados que le dieron el triunfo a Felipe Calderón, quien comenzó su sexenio con muchos de los funcionarios que habían estado en el gabinete de Vicente Fox.

A lo largo de la historia de México los hijos de familias prominentes se fueron integrando al ámbito comercial, industrial y al profesional universitario -actividades que les proporcionaban ascenso a mejores condiciones de vida y status-. Destacarse en esas funciones sociales implicaba la percepción social: ser un líder $^{5}$. Dejando en un segundo plano los espacios policiales, militares y religiosos.

Actualmente los políticos tradicionales deben aliarse con esa nueva élite que ha emergido en el mundo con el nombre de "los amos del universo", por encima de bloques comerciales, por encima de ideologías, por encima de partidos políticos, por encima de naciones.

En las sociedades contemporáneas los procesos aparentemente democráticos pretenden justificar que las decisiones políticas cuentan con la aprobación de la mayoría. El gobierno representativo es la respuesta más eficaz que los sistemas capitalistas encontraron para contrarrestar las intenciones socialistas de revolucionar la sociedad (Torres, 1998).

\footnotetext{
5 "El método de la sociología del liderazgo se ocupa de los antecedentes y estudia la composición sociológica del liderazgo institucional y de los grupos que toman las decisiones" Domohoff (1994: 207). Como se nota en referencia al caso del CMHN.
} 


\section{III.- EL PODER EN LA CONVIVENCIA SOCIAL}

Las relaciones sociales están caracterizadas por el deseo que tienen los hombres de imponer su dominio unos sobre otros. Por eso la pregunta fundamental a responder es ¿Qué motiva a un hombre a imponer su voluntad sobre los demás?

Según Hobbes el hombre tiene un deseo perpetuo de poder que acaba sólo con la muerte, porque considera que el poder que tiene nunca es el suficiente para proteger sus propiedades.

En la naturaleza del hombre existen tres causas de discordia:

A) La competencia. Causa que impulsa a los hombres a lograr seguridad.

Ejemplo: El hombre si bien reconoce que otros son más sagaces, elocuentes y cultos difícilmente llega a creer que haya muchos tan sabios como él mismo. Ya que cada uno ve su propio talento a la mano y el de los demás a distancia. Cada hombre considera que su compañero debe valorarlo del mismo modo como se valora a sí mismo. $Y$ ante la desesperación procura en la medida que puede, lograr la mayor estimación de sus contendientes infligiéndoles algún daño.

B) LA DESCONFIANZA. Causa que impulsa a los hombres a lograr seguridad. Ejemplo: Cuando el hombre emprende una jornada lleva armas y va bien acompañado. Además cuando va a dormir cierra las puertas y cuando está en su casa pone llave a sus arcas.

C) LA GLORIA. Causa que obliga a los hombres a ganar reputación (Honor). Ejemplo: Se produce cuando recurrimos a la fuerza por motivos insignificantes como una palabra, una sonrisa, una opinión distinta o cualquier otro signo de subestimación ya sea directamente en su persona o de modo indirecto en su descendencia, en sus amigos, nación, profesión o apellido.

En todas y cada una de estas causas de discordia los hombres recurren de una $u$ otra forma a la violencia. Para evitar la violencia y alcanzar la justicia, la gratitud, la modestia y la equidad deberá establecerse un pacto que descanse en la espada, de lo contrario sólo serán palabras.

En toda sociedad y "grupo humano, desde el más pequeño hasta el más grande, desde el más efímero hasta el más estable, se da la diferenciación entre los que mandan y los que obedecen, entre los que dan las órdenes y los que las acatan, entre los que toman las decisiones y los que resultan afectados por ellas" (Duverger ,1999: 23). Así, la existencia social es una lucha por la preeminencia, donde se compite por la riqueza y el poder. La pirámide del poder coincide en la mayoría de las ocasiones con la pirámide del status y de la propiedad.

Uno de los instrumentos más eficaces que utiliza el hombre para reinar sobre los demás es, la Palabra. En la vida cotidiana de toda sociedad las palabras están presentes en la formación, consolidación o destrucción del poder. "Con su ayuda 
los hombres se unen en sociedad o entran en pugna, defienden sus privilegios 0 reclaman sus derechos" (González, 1999: 15).

Nada mejor para explicarnos la importancia de la palabra que el siguiente relato griego:

Un día el amo del esclavo Esopo invitó a comer a personajes deshonestos y corruptos. Y le pidió a Esopo que le sugiriera un platillo. Este contestó: Lenguaporqué la lengua es la madre de todas las discusiones, fuente de todas las divisiones y guerras, órgano del error, de la calumnia y de la blasfemia con ella se destruyen las ciudades. Otro día el amo invitó a comer a hombres ilustres y rectos, volvió a consultar a Esopo quien recomendó el mismo platillo Lengua y dijo, porque la Lengua es el lazo de la vida civil, la llave de la Ciencia, órgano de la verdad y la razón. Con ella se construyen ciudades, se les civiliza, se les instruye, con ella se reina en las asambleas. De aquí se deduce que todo dominio político inicio con la palabra. La habilidad en la retórica, el poder en la palabra y la imposición de una lengua dan al hombre la capacidad de reinar sobre los hombres y hacer de ellos sus esclavos. (Fabula de Esopo).

El poder aparece en la convivencia social, cuando uno o varios hombres al poseer mayor fuerza numérica psicológica o moral obtienen por medio de esa fuerza la obediencia de los demás hombres.

El sentimiento de mando de ser obedecido, de tener autoridad produce en el hombre cierta satisfacción placentera. Llegándose a considerar que la extrema devoción al deseo de tener poder u obedecer puede ser un caso de vicio, adicción neurótica o incluso esquizofrenia. La extrema devoción es una situación diferente a la de aquellos hombres que sencillamente han deseado tener algo incluyendo su modesto anhelo de tener poder para realizar algo. La extrema devoción se detecta casi siempre en los casos de aquellas personas que desean tener poder por el poder mismo. Como si necesitaran algo que las identifique sin saber para que aplicarlo o porque utilizarlo.

Algunos casos de afectación extrema serían:

- $\quad$ Cuando un hombre para mantener su poder utiliza sistemáticamente como normal la mentira, el engaño, la amenaza y el insulto. Pretendiendo impresionar o amedrentar los caracteres sencillos y moderados.

- $\quad$ Aquella persona que admira y se somete con inquebrantable voluntad a cualquier mandato que ordene la persona que encarna el poder. Pero al mismo tiempo también desea poder someter a los demás. Despreciando a los débiles.

- $\quad$ Otro caso que ha engañado a muchos observadores es el de aquellas personas que desafían a toda autoridad y se indignan por toda intromisión "desde arriba". Este tipo de personas se rebela contra toda autoridad aún en contra de aquella que apoya sus intereses. Realmente su lucha se debe al disgusto que le causa su carencia de poder. Todos sus desafíos son intentos de sobreponerse a 
sus sentimientos de envidia e impotencia. Este carácter autoritario no es nunca revolucionario, preferiría llamarlo rebelde (Torres, 1998). El moderno sistema capitalista de vida mecanizado forma gente mecanizada, que dirige su vida por medio de un cálculo de medios y fines. Dado el sistema que vive, el hombre mecanizado aspira a "...ser algo separado de si mismo -miembro del parlamento, comerciante rico, juez o igualmente aburrido- y siempre logra lo que propone". "Ese es su castigo. Quien codicia una máscara termina por vivir oculto tras ella" (Wilde, 1999: 148) Imposibilitada a dejar de ser fuerza-mercancía de trabajo, la gente mecanizada está en todos lados, su vida se reduce a la posibilidad de conseguir unos cuantos pesos y aceptar de la mejor forma la vida de premios y fracasos que le depara el destino.

De esa gente común que aparentemente está satisfecha, salen los mejores candidatos que engrosarán las filas del autoritarismo social.

Pero no todo está perdido, porque todo hombre con criterio que conoce los derroteros de la vida, los sinsabores y los triunfos del espíritu tienen una vocación que le demanda conducirse hacia los valores más caros como la Justicia y el Bienestar de sus semejantes. Ojalá sea ese también el derrotero de la humanidad.

Hay hombres que desean ser el centro de acción, el medio activo de una multitud, elevar la forma interior de la propia persona a la forma de los pueblos y las edades enteras, tener el mando de la historia para conducir a su propia gente, a su pueblo o a su familia a la comprensión de los hechos sociales, esa es la razón histórica apenas consiente de cada individuo que tiene una vocación histórica.

Consecuencia del avance del proceso de transnacionalización, el mundo pareciera estar pasando en un sistema internacional dominado por los conceptos de poder basado en la seguridad militar, a otro basado en las relaciones de interdependencia transnacional.

La visión del mundo y el "régimen de verdad" -cómo deben verse las cosas según los ideólogos del poder- en México, es la política de represión supuestamente contra los carteles del narcotráfico, pero al final cualquier elemento de la sociedad está en la mira. Los valores dominantes, el tipo de orden y cómo conservarlo se presentan como la única salida; seguir la guerra impulsando la política de represión y violencia para mantener el status quo en beneficio del "establishment".

\section{IV.- EL DERECHO COMO CONTROL DEL PODER EN EDGAR BODENHEIMER}

Según Bodenheimer (2005) la anarquía aparece cuando todo el mundo es libre de hacer lo que quiera, cuando no hay estado ni gobierno que ponga límites al ejercicio arbitrario de ese poder. Los hombres son susceptibles de pasiones ante esta situación donde no hay frenos y contrapesos y terminan por oprimirse unos con otros, ante estas circunstancias la situación puede terminar en la captura del poder por un hombre o un grupo de ellos y con la sumisión de la multitud, ya que 
los hombres prefieren el yugo de un poder fuerte a una situación prolongada de caos y desorden. En el actual estado mexicano existe un clima de anarquía, a partir del poder que ha adquirido el crimen organizado y sus principales actividades, el secuestro, el narcotráfico, el tráfico de personas y las ejecuciones de individuos que previamente han sido torturados, lo más grave es que parece ser que la sociedad le empieza a parecer normal. El año 2010 termina con aproximadamente cinco mil ejecuciones y casi todas han quedado impunes. En los últimos 3 años suman más de 30,000 muertos, mucho más que los muertos en la guerra de Irak. La solución no puede ser la instauración de un estado totalitario, que a cambio de darnos seguridad y control, se extingan los derechos y las garantías por las que hemos luchado los mexicanos y que un estado despótico se instituya para prolongarse en el poder. Que el ejército gobierne las calles y actúe como policía, entraña un grave riesgo; que éste grupo con su poder bélico tenga la tentación de aceptar los beneficios de la corrupción y posteriormente vea al estado instituido como un estorbo y entonces contemple como una solución a sus conflictos dar un golpe de estado. Esta hipótesis puede encontrar apoyo en el artículo titulado "El Poder de los Generales" por el periodista Jorge Carrasco Arriaga quien afirma:

"No conforme con haber asumido su poder político de la mano de los militares para enseguida sacar al ejército a las calles, el presidente Calderón decidió entregar también a las fuerzas armadas el control operativo de la Secretaría de Seguridad Pública, al poner al frente de la subsecretaría de estrategia e inteligencia Policial al General de división DEM Javier del Real Magallanes, quien tendrá bajo su mando a la Policía Federal, el presidente complace a la Sedena y acota hasta ahora a su protegido Genaro García Luna" (Carrasco, 2008A : 6-9).

El despotismo implica un poder ilimitado de que goza un hombre sobre los súbditos a los que rige; actuando de una manera arbitraria y caprichosa de acuerdo al estado de ánimo en el que se encuentre y movido por impulsos irracionales. En un estado totalitario moderno el déspota relaciona su poder con algún ideal más elevado, al que afirma servir, sus actos los justifica en nombre de un propósito sagrado; tiene el poder ilimitado de modificar las leyes, sin expresar ningún motivo, creando en el pueblo un sentimiento de peligro e inseguridad.

Los síntomas de despotismo y del manejo arbitrario del derecho y de su manipulación para amparar los manejos a modo de los intereses del déspota resultan muy claros en la actualidad en nuestro país, tal mes el caso de la reforma petrolera, que se nos dijo no era privatizadora, sin embargo ante la presión de algunos diputados y de algunos medios de comunicación, la secretaria de energía la señora Kessel informó que el setenta y cuatro por ciento de las actividades de PEMEX se realizan por empresas extranjeras.

Esa condición no es privativa de Pemex, también se presenta en la entrega de los bienes de la nación a los particulares, preferentemente si son extranjeros. Particularmente son claros los signos de una actitud despótica del gobierno actual que refiere el periodista Jorge Carrasco Arriaga: 
"Debido a que el gobierno de Felipe Calderón no atendió las recomendaciones de la comisión Interamericana de Derechos Humanos en torno a la desaparición de un campesino guerrerense durante la guerra sucia de los setenta, el caso se turnará a la Corte Interamericana de Derechos Humanos. Esta es la primera ocasión en que el gobierno mexicano es sometido a jurisdicción internacional como consecuencia de delitos perpetrados por militares contra la población civil" (Carrasco, 2008 B: 26-27).

Ni en tiempos de Fox ocurrió esta situación cuando la misma comisión le ordenó la liberación de dos militares y dos campesinos defensores de los bosques, ya que él acató las recomendaciones, en cambio ahora la actitud de soberbia y de despotismo es clara al no acatar la recomendación de la Comisión Interamericana de los derechos Humanos. Si una de las cosas que importan al gobierno actual es dar una imagen internacional de respeto a los derechos humanos y los principios democráticos, dicha situación acarrea gran preocupación, porque ¿Qué podemos esperar los mexicanos comunes?

Para evitar la anarquía, el derecho limita el poder de los individuos particulares; para evitar el despotismo, enfrena el poder del gobierno. El derecho representa un compromiso de paz y acuerdo, por su naturaleza es restrictivo y conservador, realiza un intento por mantener un equilibrio social concediendo y asegurando ciertos derechos a los individuos y grupos, mediante la observancia de ciertas "normas", es decir reglas generales de conducta, ésta observancia va a ser impuesta por el estado a través de un sistema de coacción, pero el mecanismo coactivo no es primordial en el derecho. Por otra parte el poder representa la guerra, la disputa y la sujeción, con tendencia hacia la opresión o eliminación de los más débiles por los más fuertes, ya que en la vida social el poder es una fuerza expansiva y revolucionaria propensa a la destrucción (Bodenheimer, 2005).

El derecho es la solución para evitar tanto a la anarquía como al despotismo, sin embargo, como en la actualidad se llega al poder por medio del derecho y posteriormente el poder se ejerce por medio del derecho, el tirano ejerce el poder sin importar o violar al derecho, ya estando en el poder arregla al derecho para que sus acciones encuadren en un marco jurídico.

El respeto al derecho es un límite para no caer en la anarquía o el despotismo, el ideal del derecho evitará a la vez los dos peligros. El derecho en su forma pura y perfecta se realizará en aquel orden social en el que esté reducida al mínimo la posibilidad de abuso de poder tanto por parte de los particulares como parte del gobierno. La solución será asignarles una esfera de poder definida y circunscrita que no puedan agrandar ni trascender arbitrariamente, en interés de una vida social y ordenada, esto le da certeza al individuo de estar libre de las invasiones arbitrarias del gobierno. El derecho en conjunto, comporta igualdad y no sujeción, es una relación entre iguales y no entre superior e inferior. En su forma más pura y desarrollada, el Derecho requiere el reconocimiento, de los derechos particulares y 
prevenir o castigar toda invasión arbitraria del dominio legal de un individuo por parte de otro.

En la actualidad en el estado mexicano por determinación constitucional, según el artículo 73 de nuestra carta magna el poder ejecutivo, representado por un solo individuo denominado Presidente de los Estados Unidos Mexicanos, ejerce un poder casi omnímodo, entre otras facultades, le otorga la facultad de nombrar y remover libremente a los secretarios del despacho, al procurador general de la república, a disponer de las fuerzas armadas y a ser su jefe supremo, facultades que solo un monarca detenta. El presidente presentó al Congreso de la Unión la iniciativa que pretendía que todas las policías federales estuvieran bajo un solo mando, el de la Secretaría Federal de Seguridad y por ende bajo el mando del ejecutivo. Imaginemos que la Policía Federal Preventiva, La Agencia Federal de Investigación, La SIEDO, La Policía Fiscal, estuviesen bajo un solo mando, además del ejército, la marina, fuerza aérea, que poder de facto podría oponerse a su voluntad; la concentración de la policía bajo un solo mando es uno de los signos, más evidentes de un gobierno con tendencia totalitaria, como lo refiere Bodenheimer; por ejemplo, Chile con Pinochet o España bajo el mando de Franco, afortunadamente la mayoría de los diputados votaron en contra de dicha iniciativa, sin embargo, se puede considerar como un intento perpetrado por el ejecutivo para extender su poder.

Difícilmente podría negarse que la voluntad por alcanzar el poder sea una de las fuerzas más intensas que motivan a los individuos. En nuestro país tenemos tres casos de cómo la ambición por el poder motiva para realizar toda clase de accione; la famosa "caída del sistema en la elección en donde contendieron Carlos Salinas de Gortari y Cuauhtémoc Cárdenas", el "reconocimiento del triunfo de Fox por parte de Zedillo aún antes de que concluyera el conteo de votos, hecho que incluso priistas destacados recriminaron a Zedillo y finalmente la escandalosa serie de actos ilegales que se presentaron en la última elección, independientemente de los contendientes y de sus características.

Un individuo puede llegar a ser poderoso al ser capaz de ejercer una influencia psicológica sobre otros hombres o sobre las multitudes. Algunos pequeños pero distintivos rasgos de la personalidad de los últimos dos presidentes Fox y Calderón y de algunos de sus colaboradores más cercanos. Fox con sus respuestas ante el reclamo de sus negligencias con respuestas tales como "¿Y YO PORQUÉ?" Cuando se le preguntó de su posible intervención en la disolución del canal 40. (Fox, 2002) Otra, cuando se le cuestionó por la falta de apoyo al campo y a las universidades públicas, y sus críticas; "NI LOS VEO NI LOS OIGO?" (Fox, 2001) Su esposa Martha Sahagún involucrada junto con sus hijos en negocios turbios. Su colaborador Jorge Castañeda que fungió como Secretario de Relaciones Exteriores, se hizo llamar "canciller", no le agradaba el cargo de secretario y prefirió adoptar una denominación de las primeras repúblicas imperiales europeas. En la actualidad la respuesta en una entrevista televisada al presidente Calderón ante la pregunta si era legítimo su triunfo "Ahora sí como se dice; haiga sido como haiga sido yo gané" (Calderón 2009) menospreciando la 
seriedad de la cuestión y dejando entrever que si hizo trampa no importaba, lo importante era que había ganado. Los gobernantes actuales no consideran a los integrantes del pueblo mexicano sus iguales y por lo tanto no los consideran sujetos de un gobierno democrático, donde todos seamos iguales y nadie escape por sus actos a la acción de la justicia y en donde los poderosos puedan demoler los derechos de los más débiles. Un régimen jurídico equilibrado y justo es la solución para erradicar todos los problemas de inseguridad, comenzando por la corrupción, la impunidad y la desigualdad social.

\section{CONCLUSIÓNES:}

- El poder del Estado es la capacidad de asignar autoritativamente los valores a una sociedad en conjunto. El Estado es el poder político de una nación estructurado jurídicamente e institucionalizado. Siguiendo a Hobes en el Leviatán, encontramos que el poder de un hombre consiste en poseer medios para obtener algún bien manifiesto futuro.

- Todo poder además de basarse en el monopolio de la violencia, debe cimentarse para su ejercicio en la legitimidad y en el Consenso así como la institucionalidad para mantenerse. La Legitimidad implica la capacidad del sistema para generar y mantener la creencia de que las instituciones políticas existentes son las más apropiadas para la sociedad.

- $\quad$ El derecho debe ser el instrumento más puro y perfecto para lograr que el orden social esté sustentado en la menor posibilidad de que alguien dentro del poder formal o dentro de los grupos que son factores reales de poder abusen de sus privilegios, ni del lado de los particulares ni de parte de los representantes de los órganos del estado como gobierno.

- La clase política mexicana es el grupo socialmente dirigente y políticamente hegemónico del Estado; una minoría netamente política que deriva su poder de la monopolización de la gestión gubernamental y del manejo de los recursos públicos que establece las reglas de ascenso y mecanismos de control sobre los distintos grupos y subgrupos políticos.

- Élite es un grupo que asciende a posiciones de 'liderato' e influencia en todos los niveles sociales; se encumbran, como líderes de clase en la estructura social. Concebimos al 'líder' en un sentido amplio, para nombrar a jefes, oficiales y otras personalidades que por alguna razón, ejercen autoridad sustantiva sobre las actitudes y la conducta social en general.

- $\quad$ La solución al grave deterioro en la convivencia social mexicana es acotar y definir la esfera de poder de los gobernantes y de los particulares y que no puedan ampliar a capricho su poder ni evadir de manera discrecional la acción de la justicia. 


\section{BIBLIOGRAFÍA:}

- BODENHEIMER, Edgar. (2005), Teoría del Derecho. México: Fondo de Cultura Económica.

- CALDERÓN, Felipe. (23 de Abril de 2009). (Maerker, Denise. Entrevistador).

- CALVA, José Luis. (2005), La política económica del gobierno de Fox: Desempeño macroeconómico 2001-2004 y perspectivas. Ponencia al XXI Seminario de economía mexicana. Instituto de Investigaciones Económicas UNAM. México D.F.

- CARRASCO, J. (2008A), "El poder de los generales". Proceso, 7 de diciembre de 2008, 6-9.

- CARRASCO, J. (2008B), el gobierno de Calderón a la Corte Interamericana. Proceso, 16 de marzo de 2008, 26-27.

- Constitución Política de los Estados Unidos Mexicanos. (2004), Agenda de Amparo. México. Ed. ISEF.

- $\quad$ DOMOHOFF, W. (1994), Quien Gobierna los Estados Unidos. México. Ed. Siglo XXI.

- DUVERGER, M. (1999), Sociología política. España. Ed. Ariel.

- ESOPO. (14 Mayo 2009), Fabula del esclavo Esopo. Sitio web: ar.dir.groups.yahoo.com. Consultado: 17-03-2011.

- FOX, Vicente. (28 Diciembre 2002), Sitio web: Wikipedia.org/wiki/Vicente_Fox_Quezada. Declaraciones polémicas. Consultado: 05-03-2011.

- $\quad$ FOX, V. Sitio web: Word press/ La crónica de hoy. Consultado: 16-03-2011. (4 Noviembre 2001),

- GONZÁLEZ, E. (1999), Las Palabras y el Poder. Revista DESLINDE, (117),pp.12-20

- HOBBES, Thomas. (1997), El Leviatán. Cap. X "Del Poder". México. Fondo de Cultura Económica.

- $\quad$ MILIBAND, R. (1983), El estado en la sociedad capitalista. México. Siglo $\mathrm{XXI}$.

- $\quad$ NEIRA, Enrique (1999), El Saber del Poder. México. México. Ed. Norma.

- ORTIZ, A. (2000), XXII Congreso Internacional de la Asociación de Estudios Latinoamericanos, Hyatt Regency Miami. Marzo 16-18. Facultad de Ciencias Políticas y Sociales de la UNAM.

- $\quad$ Periódico La Jornada. La Jornada. (1997, 5 de Marzo).

- $\quad$ POE, Edgar. (1988), Narraciones Extraordinarias. "El Gato Negro". México. Ed. Porrúa. 
- $\quad$ SALIM Cabrera, Emilio y Ramírez Jacome, Gilberto. (1987), La Clase Política Mexicana, Análisis de los Rasgos y Perfiles de los Políticos Mexicanos Contemporáneos. México. Editores Asociados Mexicanos.

- $\quad$ Sitio Web www.todito.com/paginas/noticias/37849. (13 de marzo de 2002).

- $\quad$ Sitio Web www.foros.fox.presidencia.gob.mx. (17 de septiembre de 2002).

- TORRES, D. (1998), Poder. "Poder y Sociedad". №.9. México. Ed. Edicol.

- VILLEGAS, D. (1979), La sucesión: Desenlace y perspectivas. México. Cuadernos de Joaquín Mortiz.

- VULLIAMY, E. (2011), "Mientras Juárez Cae". Vivir en Juárez. Revista Letras Libres $N^{\circ} 147$. México.

- $\quad$ WILDE, O. (1999), De Profundis. España. Ed. Seix Barral.

- WRIGHT, Charles. (1993), La Elite del Poder. México. Ed. Fondo de Cultura Económica. 